\title{
COMUNICACIONES
}

\section{Método de cultivo de larvas de moscas Lucilia sericata para terapia larval}

\author{
LUIS FIGUEROA*, JORDANA FLORES* y SANDRA RODRÍGUEZ*
}

\section{A CULTURE METHOD FOR Lucilia sericata FLY LARVAE FOR USE IN MAGGOT THERAPY}

The general objectives of the present study were; 1) Describe the developmental cycle of Lucilia sericata (Calliphoridae) though the egg, larva, pupa, and imago stages, and 2) Develop a method for disinfecting the eggs of $\boldsymbol{L}$. sericata. The developmental process of this fly was observed daily, determining times required for the appearance of each different stage. The disinfection technique included successive treatment of the eggs in solutions of $0.5 \%$ sodium hypochlorite and $10 \%$ formalin after the eggs were obtained from experimentally crossing male and female flies in the laboratory. The eggs were then rinsed in sterile $0.15 \mathrm{M} \mathrm{NaCl}$, and egg samples were spread-plated on trypticase soya agar containing 5\% sheep blood, and also inoculated into in nutrient broth. The eggs of $\boldsymbol{L}$. sericata hatched after $15 \pm 3.5 \mathrm{hr}$, producing pupae after $138 \pm 17 \mathrm{hr}$, and the adults emerged after $126 \pm 21 \mathrm{hr}$. The disinfection technique used in the present study was $87 \%$ effective. It was concluded that that the complete development as well as the disinfection of the eggs could be carried out successfully in the laboratory for the production of larvae useful in maggot therapy.

Key words: Lucilia sericata, maggot therapy, fly, Chile.

\section{INTRODUCCIÓN}

La terapia larval elimina el tejido necrótico, promueve el crecimiento tisular y mejora la velocidad de curación. Las moscas más comúnmente usadas en la terapia de larvas son las pertenecientes a la familia Calliphoridae, que comparten varias propiedades biológicas ventajosas ${ }^{1}$.

De este grupo, la especie con la que trabajamos es Lucilia sericata mosca de hábitos de alimentación necrófagos, y una de las especies predominantes en la fauna cadavérica ${ }^{10,11}$. Son cosmopolitas y se presentan más frecuentes en los meses de verano ${ }^{2,3}$.

L. sericata es una mosca de tamaño mediano, fácilmente reconocibles por la coloración metálica de su cuerpo (verde), especialmente sobre el abdomen ${ }^{4}$.

La crianza de estas moscas necrófagas es técnicamente simple. Para su manejo adecuado es necesario conocer el ciclo evolutivo de la especie, así como de sus necesidades de alimentación, temperatura y humedad ${ }^{5}$.

En nuestro medio la experiencia con este tipo de tratamiento es casi desconocida y muy poco valorada por asuntos culturales prejuiciosos que nos hacen desconocer los aspectos positivos de

\footnotetext{
* Instituto de Parasitología, Facultad de Medicina, Universidad Austral de Chile. Campus Isla Teja. Valdivia. Casilla 567. Teléfono: 63-221499. Fax: 63-214475.

Trabajo financiado por la Dirección de Investigación y Desarrollo de la Universidad Austral de Chile (Proyecto DID: S-2003-55).
} 
este tipo de terapias alternativas.

El propósito de este estudio es hacer un aporte en el conocimiento de la terapia larval así como en el ciclo biológico de L. sericata, y demostrar que es posible reproducir este ciclo en laboratorio para obtener huevos desinfectados.

\section{MATERIAL Y MÉTODO}

Para la recolección de las moscas se utilizaron las trampas de Ferreira ${ }^{6}$. Se utilizó un tarro de $150 \mathrm{~mm}$ de diámetro y $200 \mathrm{~mm}$ de altura, de color negro. En la periferia de la base se realizaron 12 orificios de $13 \mathrm{~mm}$ de diámetro ubicados en círculos (por el cual ingresaban las moscas). En el fondo del tarro se depositó un pote de plástico para el cebo. Sobre este pote iba un cono, el que tenía un diámetro de base de $150 \mathrm{~mm}$ y una abertura superior de $35 \mathrm{~mm}$ de diámetro. Sobre la abertura superior del tarro se colocó una bolsa de plástico (en la que quedaban las moscas atrapadas). (Figura 1). Las trampas se colgaban a 1 metro del suelo, en zonas expuestas al sol. Como cebo se utilizaron vísceras y restos de peces. Para la clasificación se utilizaron las claves taxonómicas ya establecidas ${ }^{7}$.

Las jaulas fueron construidas con cubos de alambre de $500 \times 500 \times 500 \mathrm{~mm}$ cubiertos con malla de mosquitero. En uno de los lados se pone una manga de material ligero con un largo suficiente para trabajar en su interior. En la parte inferior de la jaula va una bandeja con agua, con el fin de mantener la humedad y evitar el exceso de material alergénico liberado al medio.

En la alimentación de las moscas se utilizo azúcar granulada y leche en polvo (como fuente de proteínas) dispuestas en pocillos. Un vaso de agua invertido sobre una placa Petri con toalla de papel absorbente provee de agua sin cubrirse de hongos.

Trozos de hígado, colocados en el fondo de tubos de PVC oscuros, proporcionaron un sustrato en el que las moscas pusieron sus huevos. De este modo se ofreció un ambiente oscuro y protegido y de fácil manejo para su recolección. Los huevos se recolectaron diariamente ${ }^{8}$.

Como término medio cada una de las cuatro jaulas contenían 500 - 1.000 moscas. Se agregaban moscas a las jaulas cada semana para repoblar ${ }^{8}$.

La cámara de cultivo de larvas se hicieron con potes de plástico de tapa hermética. Se

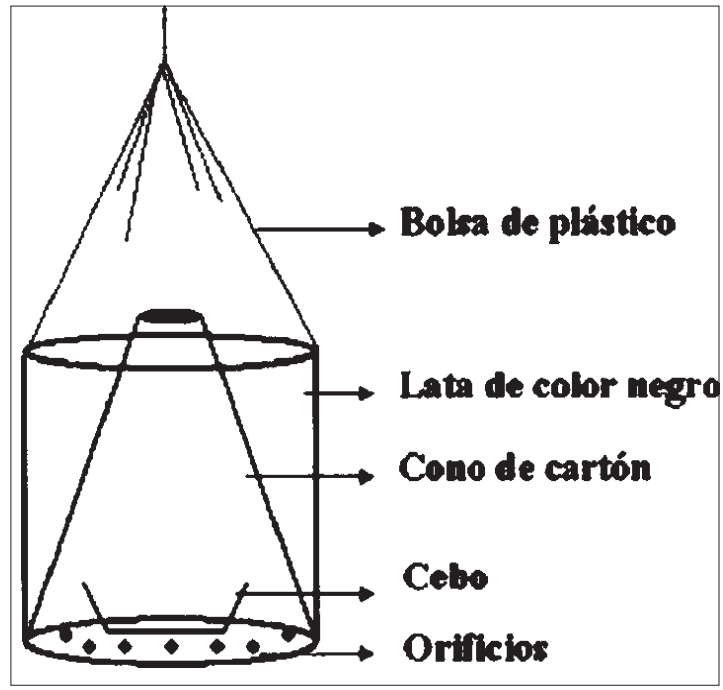

Figura 1. Trampa de captura de moscas.

cortó un espacio al centro de la tapa el que se cubrió con una tela fina que permitía la oxigenación. El pote se llena hasta la mitad con aserrín fino. En el interior, un trozo de hígado nos sirve de sustrato sobre el cual depositar los huevos recién puestos por las moscas. Al nacer las larvas, ingieren hígado y pasan por sus tres estadios larvarios antes de introducirse en el aserrín a pupar. Los adultos emergen luego de las pupas y los potes se dejan en las jaulas para aumentar su población ${ }^{8}$. Para determinar los tiempos en el desarrollo del ciclo evolutivo de $L$. sericata se reprodujo el desarrollo en 8 oportunidades, efectuando un control diario determinando sus distintos estadios.

En relación con la desinfección de las larvas, éstas nacen estériles cuando los huevos han sido desinfectados y colocados en un recipiente estéril. Las hembras ponen los huevos en masas unidos con una sustancia aglutinante por lo que deben ser separados antes de desinfectarse remojándolos en algún tipo de detergente, como sulfato de sodio o hipoclorito de sodio ${ }^{8}$.

En nuestro trabajo, la desinfección se siguió una técnica ya establecida en $1998^{9}$. Se obtuvo el mejor resultado mediante un enjuague y agitación con hipoclorito de sodio comercial diluido al $0,5 \%$ para disociar los huevos y luego esterilizarlos por 5 minutos con formalina al $10 \%$. finalmente se realizaron 3 a 4 enjuagues con suero fisiológico estéril. Toda esta etapa se realizo en un campo estéril bajo medidas básicas de asepsia. 
Se aseguró la esterilidad de los huevos cultivándolos a $27^{\circ} \mathrm{C}$ en agar tripticasa de soya y agar sangre indistintamente, además de caldo común. Se controla el desarrollo bacteriano u hongos contaminantes a las 24 - 48 horas. Además en cada esterilización se realizó cultivo de huevos en caldo triptosa, esto debido a que es fácilmente detectable cualquier indicio de contaminación mediante turbidez, y así eliminar aquellas larvas que estuvieran contaminadas.

Se realizaron 100 controles del proceso de disgregación y desinfección de los huevos midiendo el porcentaje de larvas vivas estériles a las 48 horas de incubación.

Se determinó el tiempo que se pueden almacenar las larvas estériles viables a $4^{\circ} \mathrm{C}$.

\section{RESULTADOS Y DISCUSIÓN}

La determinación de la especie $L$. sericata para el estudio y desarrollo de un método de crianza y reproducción se baso en su carácter cosmopolita y en la exitosa experiencia de otros autores demostrando su efectividad en la limpieza de heridas ${ }^{1}$.

Para determinar el tiempo necesario en el desarrollo del ciclo, efectuamos un control diario determinando sus distintos estadios (reprodujimos completamente en 8 oportunidades el ciclo de vida de L. sericata) obteniendo como resultado que las moscas luego de copular colocan sus huevos directamente en la fuente de alimento, donde su eclosión a larvas sucedió (media \pm desviación estándar) a las $15 \pm 3,5$ horas mientras que desde el estado de larvas a pupas fueron 138 $\pm 17 \mathrm{hr}$ y desde pupas a adultos, $126 \pm 21 \mathrm{hr}$. Datos que concuerdan con un autor ${ }^{13}$. Todo esto sujeto a la variable temperatura y disponibilidad de agua y alimentos.

En las condiciones de nuestro laboratorio: Temperatura de $25^{\circ} \mathrm{C}$, aproximadamente $50 \%$ de humedad, mantención de alimento y agua en forma permanente, el desarrollo del ciclo biológico de $L$. sericata desde huevo a imago fue de 11,6 días.

Los huevos fueron retirados de las jaulas diariamente, la repoblación de las jaulas se realizaba semanalmente para recuperar los ejemplares perdidos y mantener moscas siempre en su mayor período de productividad que es entre la segunda y cuarta semana de vida ${ }^{8}$.
En la disgregación de los huevos de su sustancia aglutinante los mejores resultados fueron obtenidos sumergiéndolos durante 3 minutos en hipoclorito de $\mathrm{Na}$ al 0,5 y luego desinfectar en formalina al $10 \%$ por 5 minutos con agitación constante.

Es muy importante que los huevos sean lavados con $\mathrm{NaCl}$ 0,15 M estéril, luego de cada uno de estos pasos. En este caso se realizaron 3 a 4 lavados.

Para comprobar que el proceso de desinfección fue exitoso, basándonos en lo ya propuesto ${ }^{8}$ efectuamos 100 ensayos de desinfección y control de calidad utilizando agar tripicasa de soya, adicionado o no con un 5\% de sangre, este es un medio favorable para el huevo y su eclosión a larva, ya que puede alimentarse de éste, además de que permite apreciar si hay algún tipo de contaminación. Además en cada cultivo de huevos se utilizó caldo triptosa, para detectar contaminación a través de la turbidez del medio. El margen de tiempo para determinar el éxito de la desinfección fue de 24 a 48 horas, si luego de este período no se producía contaminación podíamos asegurar la esterilidad del medio, y por lo tanto de las larvas, comprobando así que éstas eran factibles de utilizar en terapia larval.

La determinación del porcentaje de larvas vivas una vez realizado el proceso de desinfección se realizo estimando la cantidad de huevos puestos en la placa de agar, y que luego de pasadas 48 horas permanecían vivas. Se obtuvo un $4 \%$ de larvas vivas que permanecieron desinfectadas sólo hasta las 24 horas de incubación, un $87 \%$ que permaneció desinfectadas por más de 48 horas y sólo un $9 \%$ de los 100 controles realizados no resultó libre de gérmenes patógenos. (La temperatura de incubación fue de $26^{\circ}-28^{\circ} \mathrm{C}$ ).

Otro elemento necesario de determinar, fue el tiempo que se podían mantener las larvas estériles viables. Según lo señalado ${ }^{8}$, las larvas se podían refrigerar hasta 5 días a $4^{\circ} \mathrm{C}$, ya que la partir de este tiempo la muerte de las larvas sobrepasaba el 50\%. Se separaron 10 muestras al azar (teniendo en cuenta que estuvieran desinfectadas a las 48 horas de incubación) de los 100 controles realizados y llevadas a $4^{\circ} \mathrm{C}$ por 5 días. Posteriormente, se trasladaron al vivero a $25^{\circ} \mathrm{C}$ con un trozo de hígado de bovino para determinar su viabilidad. En un par de horas las larvas recuperaron su total actividad y comenzaron a ingerir el alimento, lo que les permitió llegar al 
estado de imago y darnos la certeza de que las larvas desinfectadas pueden ser refrigeradas por un máximo de 5 días, ya que después de esto la viabilidad se pierde en un gran porcentaje.

\section{RESUMEN}

Los objetivos generales del estudio fueron: 1) Describir el ciclo de desarrollo de Lucilia sericata (Calliphoridae), en sus fases de huevo, larva, pupa e imago y 2) Adaptar una técnica para desinfectar huevos de L. sericata y la posterior obtención de larvas estériles. El control del desarrollo se efectuó determinando diariamente sus distintos estadios. Para la técnica de desinfección, los huevos se sumergieron sucesivamente en soluciones de hipoclorito de sodio $0,5 \%$ y formalina $10 \%$, y luego lavados en $\mathrm{NaCl}$ 0,15 M. Para controlar la calidad de desinfección, una muestra de huevos fue distribuida en agar tripticasa de soya con $5 \%$ de sangre y en caldo común.

El desarrollo de L. sericata en el laboratorio mostró que los huevos y su eclosión a larvas ocurrió (media \pm desviación estándar) a las $15 \pm$ $3,5 \mathrm{hr}$ mientras que de larvas a pupas $138 \pm 17$ hr y de pupa a adultos $126 \pm 21 \mathrm{hr}$. La técnica de desinfección de los huevos de L. sericata mostró un $87 \%$ de efectividad.

\section{REFERENCIAS}

1.- SHERMAN RA, HALL M J R, THOMAS S. Medicinal maggots: An ancient remedy for some contemporary afflictions. Ann Rev Entomol 2000; 45: 55-81.

2.- SHINKMAN R. Maggots, leeches are making a comeback in modern medicine. Mod Healthcare 2000; 20: 54-5.

3.- GUIMARÀES J H, PAPAVERO N, PRADO P. As miíases na regiâo Neotropical (Identificacâo, Biología, Bibliografía). Revta Bras Zool 1983; 1: 239-416.

4.- KETTLE DS. Medical and Veterinary Entomology. Second Edition. Department of Entomology. University of Queensland. Australia 1995: 53.

5.- SHERMAN R A, WYLE AF. Low - cost, low maintenance rearing of maggots in hospitals, clinics and schools. Am J Med HYG 1996; 54: 38-41.

6.- GUIMARÀES J H, PAPAVERO N, PRADO P. As miíases na regiâo Neotropical (Identificacâo, Biología, Bibliografía). Revta Bras Zool 1983; 1: 239-416.

7.- GREENBERG B. Flies and disease. Ecology, classification and biotic association. USA: Princeton University Press 1971; Vol I: 1-856.

8.- SHERMAN R A, WYLE A F. Low-cost, lowmaintennance rearing of maggots in hospital clinical and schools. Am J Med HYG 1996; 54: 38-41.

9.- MUMCUOGLU K Y, INGBER A, GILEAD L, et al. Maggot therapy for the treatment of diabetic foot ulcers. Diab Care 1998; 21: 2030-1.

10.- FIGUEROA L, LINHARES A. Sinantropía de los Calliphoridae (Diptera) de Valdivia. Chile. Neotropica Entomol 2002; 31(2): 233-9.

11.- ATIAS A. Parasitología Médica. Fac. de Medicina Universidad de Chile 1999; 450-64.

Correspondencia a:

e-mail:1figuero@uach.cl 